\title{
CORRECTION
}

\section{Correction to: Management of glucocorticoid-induced osteoporosis}

\author{
Osvaldo D. Messina ${ }^{1} \cdot$ Luis Fernando Vidal $^{2} \cdot$ Maritza Vidal Wilman $^{2} \mathbb{D} \cdot$ Irene E. M. Bultink ${ }^{3} \cdot$ Hennie G. Raterman ${ }^{4}$. \\ William Lems ${ }^{5}$
}

Accepted: 15 July 2021 / Published online: 23 July 2021

(c) Springer Nature Switzerland AG 2021

\section{Correction to: \\ Aging Clinical and Experimental Research (2021) 33:793-804 \\ https://doi.org/10.1007/s40520-021-01823-0}

In the published article the author name Maritza Vidal Wilman was processed incorrectly and now it has been rectified.

The original article has been updated.

Publisher's Note Springer Nature remains neutral with regard to jurisdictional claims in published maps and institutional affiliations.

The original article can be found online at https://doi.org/10.1007/ s40520-021-01823-0.

Maritza Vidal Wilman

maritza.vidal55@hotmail.com

1 Investigaciones Reumatológicas y Osteológicas (IRO)

Medical Center, Buenos Aires, Argentina

2 Centro de Diagnóstico de Osteoporosis y Enfermedades Reumáticas (CEDOR), Lima, Perú

3 Department of Rheumatology, Amsterdam UMC, Amsterdam Rheumatology and Immunology Center, Vrije Universiteit Amsterdam, De Boelelaan 1117, 1081 HV Amsterdam, The Netherlands

4 Department of Rheumatology, North West Clinics, Postbus 501, 1800 AM Alkmaar, The Netherlands

5 Department of Rheumatology, Amsterdam UMC, Location VU University Medical Centre Amsterdam, Amsterdam, Noord-Holland, The Netherlands 